\title{
Dentoskeletal and tooth-size differences between Syrian and Hungarian adolescents with Class II division 1 malocclusion: a retrospective study
}

\author{
Alaa Al Ayoubi* (i), Alireza Khandan Dezfully and Melinda Madléna* (i)
}

\begin{abstract}
Objectives: Malocclusion features differ across various populations and ethnicities. At this time, no data are available regarding the dentofacial differences between Syrian and European adolescents with Class II division 1 malocclusion, which is one of the most frequently treated pathologies in orthodontic practice. The present combined cephalometric and tooth-size study aimed to compare the dentoskeletal and tooth-size characteristics of Syrian and Hungarian adolescents with Class II division 1 malocclusion.

Results: Class II division 1 malocclusion in Hungarian adolescents was a sagittal discrepancy, while in Syrian adolescents, it was a result of excessive vertical development. Syrian adolescents had a significantly excessive vertical development when compared with Hungarian adolescents, regardless of $\operatorname{sex}(p<0.01)$. Hungarian boys had significantly more protruded maxillae $(p<0.001)$ and less retruded mandibles $(p<0.01)$ when compared with Syrian boys, while Hungarian girls had significantly shorter mandibles relative to those of Syrian girls $(p<0.01)$. Syrian girls had significantly more protrusive lower incisors $(p<0.001)$, accompanied by significantly larger anterior tooth-size ratios when compared to Hungarian girls $(p<0.001)$. In conclusion, these findings underscore the importance of considering ethnic differences during orthodontic diagnosis and may have implications for optimizing orthodontic treatments in Syrian and Hungarian adolescents with Class II division 1 malocclusion.
\end{abstract}

Keywords: Ethnic differences, Dentoskeletal structure, Tooth size, Class II division 1 malocclusion

\section{Introduction}

Although several studies have reported ethnic differences in dentoskeletal structure and tooth-size characteristics [1-8], limited studies have investigated these differences in Class II division 1 (Class II/1) malocclusion [9-11]. With prevalences of $16 \%$ and $23.5 \%$ in Syrian and Hungarian adolescents, respectively $[12,13]$, this is one of

*Correspondence: alaa.alayoubi@outlook.com; madlenamelinda784@gmail. com

Department of Orthodontics and Pediatric Dentistry, Faculty of Dentistry,

University of Szeged, Tisza Lajos körút 64-66, Szeged 6720, Hungary the most frequently seen malocclusions in orthodontic practice.

Various factors cause Class II/1 malocclusion. However, conflicting results, possibly due to ethnic variations, have prevented their general characterization [9-11]. Likewise, tooth-size ratios show ethnic differences $[4$, 5]. In view of recent migration trends, especially from the Middle-East toward Europe, these findings underscore the need for updated comparisons of dentoskeletal and tooth-size characteristics across ethnicities [14]. Although some research has considered some dentoskeletal and tooth-size characteristics of Syrian populations $[15,16]$ or Hungarian populations $[17,18]$, no study has

(c) The Author(s) 2020. This article is licensed under a Creative Commons Attribution 4.0 International License, which permits use, sharing, adaptation, distribution and reproduction in any medium or format, as long as you give appropriate credit to the original author(s) and the source, provide a link to the Creative Commons licence, and indicate if changes were made. The images or other third party material in this article are included in the article's Creative Commons licence, unless indicated otherwise in a credit line to the material. If material is not included in the article's Creative Commons licence and your intended use is not permitted by statutory regulation or exceeds the permitted use, you will need to obtain permission directly from the copyright holder. To view a copy of this licence, visit http://creativeco mmons.org/licenses/by/4.0/. The Creative Commons Public Domain Dedication waiver (http://creativecommons.org/publicdomain/ zero/1.0/) applies to the data made available in this article, unless otherwise stated in a credit line to the data. 
compared these characteristics between Syrian and European (Hungarian) adolescents.

Despite the evaluation of Class II/1 malocclusion in multiple studies, the following factors limit their results:

- The influence of skeletal age variations on results' reliability has been neglected, since most Class II/1 malocclusion studies grouped patients by their chronological age [9-11, 19-23].

- While most studies selected patients with Class II/1 malocclusion based on their dental relationships (molar and/or incisor relationships) [9, 11, 20, 21, 23-25], these patients might have had either Class I or Class II skeletal pattern; studies on both skeletal and dental Class II/1 malocclusion are lacking [10, 22, 26].

- The dentoskeletal structure of individuals with Class II/1 malocclusion was analyzed during childhood [10, 11], adulthood [26], or by including subjects across a wide age-range-early childhood to adulthood [19-21]. However, most orthodontic patients seek treatment during adolescence, during which all treatment options and techniques are available.

- Limited studies have included cephalometric and tooth-size measurements in the same investigation [1]. This combination could comprehensively diagnose the malocclusion and elucidate the complex relationship between its components.

\section{Objective}

This combined cephalometric and tooth-size study aimed to compare the skeletal morphology, dental position, and tooth size of skeletal age- and sex-matched Syrian and Hungarian adolescents with skeletal and dental Class II/1 malocclusion.

\section{Main text}

\section{Materials and methods}

\section{Subjects}

The sample size assumed a bilateral two-sample $t$ test for assessment. According to previous similar dentoskeletal and tooth-size studies [5, 27], effect sizes were estimated from the SNGoMe angle $5.80^{\circ}\left( \pm 5.78^{\circ}\right)$ [27], and the upper central-incisor width $0.54( \pm 0.52) \mathrm{mm}[5]$, respectively. With a significance level alpha $=0.05$ (two-sided) and $80 \%$ power, the required sample size was calculated to detect standardized effect sizes of $1.00\left(5.80 / 5.78^{\circ}\right)$ and $1.03(0.54 / 0.52 \mathrm{~mm})$ for dentoskeletal and toothsize comparisons, respectively. Sample size calculation showed that 17 patients were required for each sex subgroup in each ethnic group [28]; lateral cephalograms and dental casts of 86 untreated patients with skeletal and dental Class II/1 malocclusion were thus included in this study. The study sample comprised two groups based on ethnicity-group 1, 43 Syrian patients selected from a private orthodontic office in Damascus, Syria; and group 2, 43 Hungarian patients selected from the Department of Orthodontics and Pediatric Dentistry, Faculty of Dentistry, University of Szeged, Hungary. Both groups included 24 girls and 19 boys. Each patient in group 1 was matched with a patient in group 2 by sex and skeletal age. To eradicate bias caused by growth variation, skeletal age was assessed from lateral cephalograms according to the method developed by Baccetti et al. [29]. Age and sex distributions of the study sample are summarized in Table 1.

The inclusion criteria were as follows:

- Age, 12-17 years.

- Syrian ethnicity for group 1; Hungarian ethnicity for group 2.

- Overjet $>4 \mathrm{~mm}$ without upper incisor retroclination (U1/NA angle $\geq 22^{\circ}$ ).

- Half-unit or greater bilateral distal occlusion with permanent dentition.

- ANB angle $>4^{\circ}$ with a convex facial profile.

- No extractions, interproximal restorations, or conditions affecting the mesio-distal teeth diameter.

The exclusion criteria were patients with history of orthodontic treatment, trauma, or craniofacial syndromes. The Human Investigation Review Board at the University of Szeged (151/2018-SZTE) approved this

Table 1 Age and sex distributions of the study groups

\begin{tabular}{|c|c|c|c|c|c|c|c|}
\hline & \multicolumn{3}{|l|}{ Boys } & \multicolumn{3}{|l|}{ Girls } & \multirow[t]{2}{*}{ Total } \\
\hline & Mean age \pm S.D (y) & Age range $(y)$ & $\begin{array}{l}\text { Sample size } \\
\text { (n) }\end{array}$ & Mean age \pm S.D (y) & Age range (y) & $\begin{array}{l}\text { Sample size } \\
\text { (n) }\end{array}$ & \\
\hline Syrians & $14.1 \pm 1.7$ & $11.7-17.3$ & 19 & $14.6 \pm 1.4$ & $11.9-17.1$ & 24 & 43 \\
\hline Hungarians & $14.0 \pm 2.0$ & $11.4-17.6$ & 19 & $14.6 \pm 1.8$ & $11.3-17.7$ & 24 & 43 \\
\hline Total & & & 38 & & & 48 & 86 \\
\hline
\end{tabular}


retrospective cross-sectional study. The participants or their parent/legal guardian provided written informed consent to participate in this study.

\section{Cephalometric measurements}

Pretreatment lateral cephalograms were obtained for each patient in both ethnic groups using the same protocol (head in natural position and teeth in maximal intercuspation). Magnification was corrected to 1:1 since the cephalograms were acquired with two different machines. The cephalometric measurements used herein were derived from the analyses developed by Jarabak, Steiner, and the University of Bonn [30-32]. Definitions of the cephalometric measurements are presented in Additional file 1: Table S1. Landmarks and reference lines are shown in Additional file 2: Figure S1. A special orthodontic software (OnyxCeph $3^{\mathrm{TM}}$, Image Instruments $\mathrm{GmbH}$, Chemnitz, Germany) was used by one investigator to digitize and analyze all lateral cephalograms.

\section{Dental-cast measurements}

The teeth in both arches-from the right first permanent molar to the left first permanent molar-were measured at the largest mesio-distal dimension [33], to the nearest $0.01-\mathrm{mm}$, by one investigator using a universal digital caliper (MIB Messzeuge GmbH, Spangenberg, Germany). Bolton's overall ratio ( $\sum$ widths of the mandibular 6-6/ Ewidths of the maxillary $6-6 \times 100$ ) [34] and Bolton's anterior ratio ( $\sum$ widths of the mandibular $3-3 /$ Ewidths of the maxillary $3-3 \times 100$ ) [34] were calculated and used in statistical analyses.

\section{Method error}

To establish intra-examiner reliability, measurements of 20 randomly selected cephalograms and casts were replicated several weeks later by the same investigator. Dahlberg's formula [35] showed random errors $\leq 0.40 \mathrm{~mm}$ and $\leq 0.44^{\circ}$ for linear and angular cephalometric variables, respectively, and $\leq 0.17 \mathrm{~mm}$ for tooth-size measurements. Paired sample $t$-tests showed no systematic error $(\mathrm{p}>0.05)$. Intraclass correlation coefficients were $>0.95$.

To establish inter-examiner reliability, measurements of 20 randomly selected cephalograms and casts were replicated again by another investigator. Random errors were $\leq 0.46 \mathrm{~mm}$ and $\leq 0.48^{\circ}$ for linear and angular cephalometric variables, respectively, and $\leq 0.33 \mathrm{~mm}$ for tooth-size measurements. Systematic error was absent $(p>0.05)$. Intraclass correlation coefficients were $>0.93$.

\section{Statistical analyses}

Descriptive statistics of each variable were calculated using SPSS software 24.0 (SPSS Inc., Chicago, USA). Intergroup comparisons were performed using $t$ - or
Mann-Whitney $U$-tests, depending on data normality (according to Shapiro-Wilk's test). For normally-distributed data, two-sample or Welch's $t$-tests were used depending on equality of variance (according to $F$-test). The level of statistical significance was set at 0.05 .

\section{Results}

Results for sex-based comparisons between the two ethnic groups are presented in Table 2.

Results for overall comparisons between the two ethnic groups are presented in Additional file 3: Table S2.

\section{Cephalometric comparisons}

Sagittal comparisons revealed that Hungarian boys had significantly more protruded maxillae (SNA) than their Syrian counterparts $(p<0.001)$, while Syrian boys had significantly more retruded mandibles (SNB) $(p<0.01)$. Hungarian girls had significantly smaller mandibular lengths $(\mathrm{Go}-\mathrm{Gn})$ than their Syrian counterparts $(p<0.01)$ (Fig. 1).

Vertical measurements (ArGoMe, $\sum$ Bjork, SN/GoMe, and S-Go:N-Me) showed significant differences $(p<0.01)$ between Syrian and Hungarian adolescents, regardless of sex, indicating a hyperdivergent facial pattern in Syrian ethnicity (Additional file 3: Table S2).

Dental measurement results revealed that Syrian girls had significantly more protruded lower incisors (L1/ NB and L1-NB) $(p<0.001)$ than Hungarian girls. These observations did not extend to the male populations (Table 2).

\section{Tooth-size comparisons}

Syrian girls had significantly greater anterior tooth-size ratios than Hungarian girls $(p<0.001)$. Syrian and Hungarian boys showed no such difference (Table 2).

\section{Discussion}

This study evaluated the effects of ethnic variations on dentoskeletal and tooth-size characteristics of Syrians and Hungarians adolescents with Class II/1 malocclusion. As most dentoskeletal variations can be ascribed to sex, age (maturity stage), and ethnicity [9], and most tooth-size variations can be ascribed to sex and ethnicity $[4,5]$, this study compared sex- and skeletal age-matched individuals to yield clear conclusions on the impact of ethnicity on dentoskeletal and tooth-size characteristics.

Skeletal comparisons showed that sagittal measurements significantly differed between the two groups-Hungarian boys had more protruded maxillae compared to Syrian boys, while Hungarian girls had significantly shorter mandibles than Syrian girls (Fig. 1). These observations in Hungarian adolescents support those of a previous study [19], which found 
Table 2 Sex-based comparison of cephalometric measurements and tooth-size ratios between the two ethnic groups

\begin{tabular}{|c|c|c|c|c|c|c|c|c|c|c|}
\hline & \multicolumn{5}{|l|}{ Boys } & \multicolumn{5}{|l|}{ Girls } \\
\hline & \multirow[t]{2}{*}{$\begin{array}{l}\text { Syrians } \\
(n=19) \\
\text { Mean } \pm \text { S.D }\end{array}$} & \multirow[t]{2}{*}{$\begin{array}{l}\text { Hungarians } \\
(n=19) \\
\text { Mean } \pm \text { S.D }\end{array}$} & \multicolumn{2}{|c|}{$\begin{array}{l}95 \% \mathrm{Cl} \\
\text { of Mean } \\
\text { difference }\end{array}$} & \multirow[t]{2}{*}{$p$-value } & \multirow[t]{2}{*}{$\begin{array}{l}\text { Syrians } \\
(n=24) \\
\text { mean } \pm \text { S.D }\end{array}$} & \multirow[t]{2}{*}{$\begin{array}{l}\text { Hungarians } \\
(n=24) \\
\text { Mean } \pm \text { S.D }\end{array}$} & \multicolumn{2}{|c|}{$\begin{array}{l}95 \% \mathrm{Cl} \\
\text { of Mean } \\
\text { difference }\end{array}$} & \multirow[t]{2}{*}{$p$-value } \\
\hline & & & $\mathbf{L}$ & $U$ & & & & $\mathbf{L}$ & $U$ & \\
\hline \multicolumn{11}{|c|}{ Cephalometric measurements $\partial$} \\
\hline \multicolumn{11}{|c|}{ Skeletal measurements } \\
\hline \multicolumn{11}{|l|}{ Sagittal values } \\
\hline SNA $\left(^{\circ}\right)$ & $79.70 \pm 2.72$ & $83.43 \pm 2.79$ & -5.54 & -1.91 & $<0.001$ & $81.06 \pm 2.50$ & $80.69 \pm 3.49$ & -1.40 & 2.13 & 0.679 \\
\hline SNB $\left(^{\circ}\right)$ & $73.81 \pm 2.93$ & $76.73 \pm 2.82$ & -4.81 & -1.03 & 0.003 & $74.05 \pm 2.85$ & $74.24 \pm 3.62$ & -2.09 & 1.70 & 0.840 \\
\hline ANB $\left(^{\circ}\right)$ & $5.89 \pm 1.46$ & $6.70 \pm 1.19$ & -1.69 & 0.06 & 0.068 & $7.01 \pm 1.75$ & $6.45 \pm 1.56$ & -0.41 & 1.52 & 0.249 \\
\hline ANS-PNS (mm) & $56.44 \pm 4.95$ & $56.68 \pm 3.12$ & -2.97 & 2.49 & 0.859 & $55.00 \pm 4.04$ & $53.39 \pm 3.15$ & -0.50 & 3.71 & 0.132 \\
\hline Go-Gn (mm) & $73.13 \pm 6.18$ & $71.38 \pm 5.05$ & -1.96 & 5.47 & 0.345 & $71.93 \pm 4.58$ & $67.77 \pm 4.50$ & 1.52 & 6.79 & 0.003 \\
\hline \multicolumn{11}{|l|}{ Vertical values } \\
\hline $\operatorname{ArGoMe}\left({ }^{\circ}\right)$ & $124.08 \pm 7.88$ & $119.11 \pm 6.25$ & 0.30 & 9.66 & 0.038 & $125.29 \pm 9.62$ & $120.18 \pm 6.67$ & 0.30 & 9.92 & 0.038 \\
\hline$\sum$ Bjork $\left(^{\circ}\right)$ & $398.33 \pm 5.75$ & $392.16 \pm 5.85$ & 2.35 & 9.99 & 0.002 & $400.14 \pm 6.43$ & $394.53 \pm 6.75$ & 1.78 & 9.44 & 0.005 \\
\hline $\operatorname{Ar}-\mathrm{Go}(\mathrm{mm})$ & $41.56 \pm 5.11$ & $44.48 \pm 4.70$ & -6.15 & 0.30 & 0.074 & $42.01 \pm 4.81$ & $39.98 \pm 4.17$ & -0.58 & 4.65 & 0.124 \\
\hline SN/GoMe $\left(^{\circ}\right)$ & $38.33 \pm 5.76$ & $32.16 \pm 5.85$ & 2.35 & 9.99 & 0.002 & $40.14 \pm 6.43$ & $34.53 \pm 6.75$ & 1.78 & 9.44 & 0.005 \\
\hline S-Go:N-Me (\%) & $61.64 \pm 4.09$ & $66.71 \pm 4.51$ & -7.90 & -2.24 & 0.001 & $60.62 \pm 4.69$ & $64.47 \pm 5.42$ & -6.80 & -0.90 & 0.012 \\
\hline \multicolumn{11}{|c|}{ Dental measurements } \\
\hline U1/NA $\left(^{\circ}\right)$ & $26.97 \pm 4.18$ & $26.98 \pm 3.71$ & -2.62 & 2.58 & 0.989 & $26.44 \pm 2.60$ & $28.16 \pm 4.32$ & -3.81 & 0.36 & 0.102 \\
\hline L1/NB $\left(^{\circ}\right)$ & $29.37 \pm 5.56$ & $28.80 \pm 5.23$ & -2.99 & 4.11 & 0.750 & $35.45 \pm 4.34$ & $27.50 \pm 6.05$ & 4.89 & 11.01 & $<0.001$ \\
\hline U1-NA (mm) & $5.86 \pm 2.06$ & $4.90 \pm 2.11$ & -0.42 & 2.33 & 0.166 & $6.21 \pm 2.15$ & $5.39 \pm 2.29$ & -0.47 & 2.11 & 0.208 \\
\hline L1-NB (mm) & $8.22 \pm 2.03$ & $6.88 \pm 2.08$ & -0.01 & 2.69 & 0.052 & $9.73 \pm 1.96$ & $5.52 \pm 1.88$ & 3.09 & 5.32 & $<0.001$ \\
\hline \multicolumn{11}{|l|}{ Tooth-size ratios $\partial$} \\
\hline Anterior ratio (\%) & $80.55 \pm 2.95$ & $79.42 \pm 2.08$ & -0.57 & 2.81 & 0.186 & $80.81 \pm 2.60$ & $77.89 \pm 2.42$ & 1.46 & 4.38 & $<0.001$ \\
\hline Overall ratio (\%) & $92.74 \pm 1.80$ & $92.79 \pm 2.33$ & -1.42 & 1.32 & 0.941 & $92.92 \pm 1.65$ & $91.87 \pm 1.98$ & 0.00 & 2.11 & 0.051 \\
\hline
\end{tabular}

Italic values indicate significance of $p$ value $(p<0.05)$

$\partial t$-tests for independent variables

S.D Standard deviation, $C /$ Confidence interval

Class II/1 Caucasian boys with maxillary protrusion and Class II/1 Caucasian girls with shorter-than-average mandibular length. Although Syrian adolescents had relatively normal maxillary position and mandibular length as compared with Hungarian adolescents, their mandibles were posteriorly positioned. This was evident in Syrian boys with significantly smaller SNB angles than Hungarian boys who had relatively normal mandibular position. In contrast, Syrian girls also had restricted mandibles; however, the diminished mandibular sizes of Hungarian girls were pronounced enough to cause a non-significant difference in SNB measurements between the two female populations. NonCaucasian studies reported similar findings of normal maxillary position and retruded mandible in Class II/1 Syrian subjects [20, 22, 23, 26]. Contrarily, some Caucasian studies reported varying findings with normally positioned mandibles and protruded maxillae [24, 25].
The involvement of different ethnicities across various studies may explain the inconsistent findings.

Many authors have recognized the importance of excessive vertical development in the determination of mandibular position $[10,20,26]$. Thus, retruded mandibles of Syrian adolescents in this study can be explained with respect to the vertical plane: Syrian adolescents, in comparison to Hungarian adolescents, regardless of sex, had hyperdivergent facial patterns (Fig. 1). This finding agrees with those of other studies that compared nonCaucasian and Caucasian Class II patients [9, 10, 27].

The position of dentition, relative to the skeletal structure, is another important aspect of Class II/1 malocclusion. The only significant difference in the dental position found in this study was related to the lower incisors and was evident among girls. Syrian girls had more protrusive lower incisors than Hungarian girls. Status on the position of lower incisors in patients with Class II/1 malocclusion remains unclear. Most non-Caucasian studies 

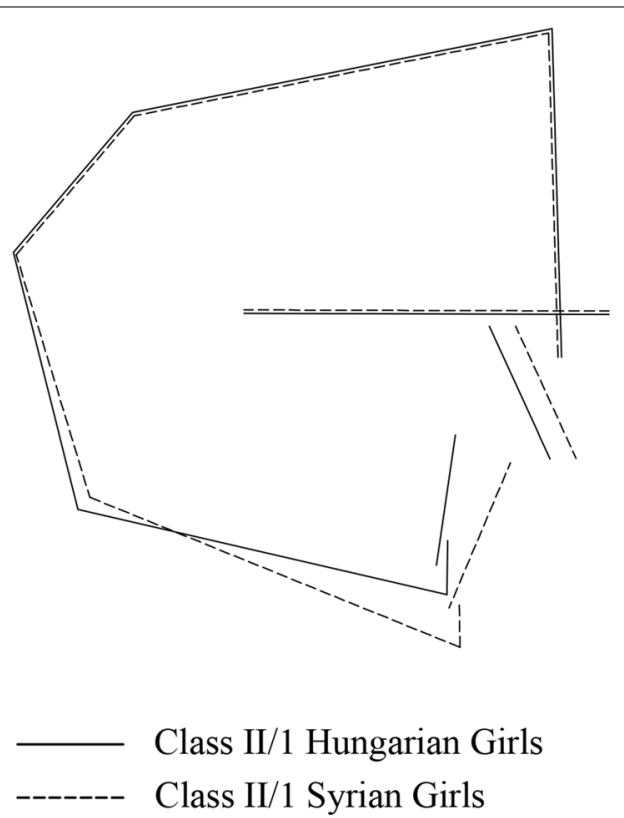
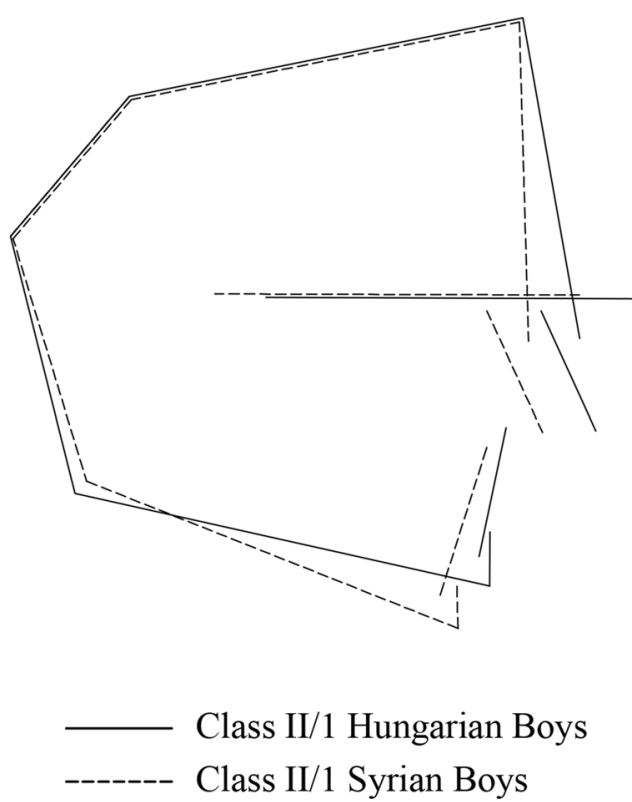

Fig. 1 Sex-based comparisons between Syrian and Hungarian adolescents with Class II/1 malocclusion

have reported protruded lower incisors [20-22, 26], and two comparative studies $[9,10]$ support ethnic variations in lower incisor position between non-Caucasian and Caucasian populations. Since a tooth-size excess with space limitation might cause incisor protrusion, the larger anterior tooth-size ratios of Syrian girls relative to Hungarian girls might further account for their lower incisor protrusion. This is because the large anterior tooth-size ratios of Syrian girls reflect a relative toothsize excess in the lower anterior region. The significant difference in anterior tooth-size ratio between Syrian and Hungarian girls can be attributed to ethnic variations $[4$, 5].

\section{Clinical implications}

First, because Class II/1 malocclusion in Hungarian adolescents represents sagittal discrepancy (protruded maxillae in boys; short mandibles in girls), treatment strategies should aim to inhibit maxillary growth using extra-oral forces in Hungarian boys and enhance mandibular growth using functional appliances in Hungarian girls. Second, since Syrian adolescents had considerable vertical tendencies and most orthodontic treatment mechanics tend to open the bite, greater care should be exercised to control the vertical dimension when treating Syrian adolescents compared with Hungarian adolescents. Treatment strategies for Class II/1 Syrian adolescents should aim to alter the extent and direction of vertical facial growth and prevent posterior mandibular rotation. Finally, Class II/1 Syrian girls exhibited more protrusive lower incisors with relative tooth-size excess in the lower anterior segment, which affects treatment objectives regarding the optimal final position of these teeth. Therefore, a more interproximal reduction might be a better indication for Syrian girls than Hungarian girls, if the treatment decision is to decrease protrusion. Contrarily, protruded lower incisors, more than the standard levels, might be acceptable outcomes in Syrian girls.

\section{Conclusions}

Class II/1 treatment strategies for Hungarian adolescents are not applicable to Syrian adolescents, because.

- Class II/1 malocclusion reflects sagittal discrepancy in Hungarian adolescents (protruded maxillae in boys; short mandibles in girls), while it was caused by excessive vertical growth among Syrian adolescents, regardless of sex.

- Class II/1 Syrian girls have more protrusive lower incisors with a relative tooth-size excess in the lower anterior region compared with Class II/1 Hungarian girls.

Thus, even among patients with the same malocclusion type, dentoskeletal and tooth-size characteristics can vary with ethnicity. Hence, orthodontists should 
be aware of this variation to optimize their differential diagnosis and treatment planning.

\section{Limitations}

Although sample size estimation showed sufficient sample sizes, they were relatively small. This was the major drawback of the present study; therefore, the results should be interpreted with caution, and additional studies with larger sample sizes are warranted.

\section{Supplementary information}

Supplementary information accompanies this paper at https://doi. org/10.1186/s13104-020-05115-0.

Additional file 1: Table S1. Definitions of the cephalometric measurements used in this study.

Additional file 2: Figure S1. Landmarks and reference lines used in this study.

Additional file 3: Table S2. Overall comparison of cephalometric measurements and tooth-size ratios between the two ethnic groups.

\section{Abbreviation}

Class II/1: Class II division 1

\section{Acknowledgements}

Not applicable.

\section{Authors' contributions}

AA contributed to the planning, data acquisition, analysis of data, interpretation of the results and writing of the manuscript. AK contributed to analysis of data, interpretation of the results and writing of the manuscript. MM contributed to the planning, analysis of data, interpretation of the results and writing of the manuscript. All authors read and approved the final manuscript.

\section{Funding}

Open access funding was provided by the University of Szeged (SZTE).

\section{Availability of data and materials}

The datasets generated and analyzed during the current study are available from the corresponding authors on reasonable request.

\section{Ethics approval and consent to participate}

The present study was approved by the Human Investigation Review Board at the University of Szeged (151/2018-SZTE). Written informed consent to participate in this study was provided by the participants or their parent/legal guardian.

\section{Consent for publication}

Not applicable.

\section{Competing interests}

The authors declare that they have no competing interests.

Received: 17 April 2020 Accepted: 26 May 2020

Published online: 03 June 2020

\section{References}

1. Vela E, Taylor RW, Campbell PM, Buschang PH. Differences in craniofacial and dental characteristics of adolescent Mexican Americans and European Americans. Am J Orthod Dentofacial Orthop. 2011;140(6):839-47.
2. Abbassy MA, Horiuchi M, Harouny NE, Kanno Z, Ono T. Comparative cephalometric study of Class I malocclusion in Egyptian and Japanese adult females. Orthod Waves. 2012;71(2):59-65.

3. Trivedi K, Singh S, Shivamurthy DM, Doshi J, Shyagali T, Patel B. Analysis of cephalometrics for orthognathic surgery: determination of norms applicable to Rajasthani population. Natl J Maxillofac Surg. 2010;1 (2):102-7.

4. Kumar TP, Chitra P. Determination of bolton norms for Indian population sample. Orthod J Nepal. 2017;7(1):33-6.

5. Lavelle CLB. Maxillary and mandibular tooth size in different racial groups and in different occlusal categories. Am J Orthod. 1972;61(1):29-37.

6. Al Taki A, Abuhijleh E, Haider K. Dentofacial cephalometric values for emirati adults with normal occlusion and well-balanced faces. Smile Dent J. 2010:5(4):6-10.

7. Abbassy MA, Abushal A. Differences in dentofacial characteristics of Class I malocclusion between Saudi and Japanese adult females. J Orthod Sci. 2015;4(3):86-91.

8. Afifi A, Taha M, Nassar E. Saudian norms of Mc Namara's cephalometric analysis. Egypt Orthod J. 2008;33:41-9.

9. Phelan T, Buschang PH, Behrents RG, Wintergerst AM, Ceen RF, Hernandez A. Variation in Class II malocclusion: comparison of Mexican mestizos and American whites. Am J Orthod Dentofacial Orthop. 2004;125(4):418-25.

10. Ishii N, Deguchi T, Hunt NP. Morphological differences in the craniofacial structure between Japanese and Caucasian girls with Class II division 1 malocclusions. Eur J Orthod. 2002;24(1):61-7.

11. Rana N, Qu YY, Wei Y, Liu L. Comparison of cephalometric hard and soft tissues of adolescents with angle Class II division 1 malocclusion between Northern Chinese population and Northern Indian Population. Chin J Dent Res Off J Sci Sect Chin Stomatol Assoc CSA. 2017;20(1):33-42.

12. Alatrach $A B$, Saleh FK, Osman E. The prevalence of malocclusion and orthodontic treatment need in a sample of Syrian children. Eur Sci J. 2014;10(30):230-47.

13. Gábris K, Márton S, Madléna M. Prevalence of malocclusions in Hungarian adolescents. Eur J Orthod. 2006;28(5):467-70.

14. Abuhijleh E, Al Taki A, Rahhal A. The cephalometric norms of various ethnicities and their significance. Acta Sci Dent Sci. 2019;3(8):21-2.

15. Nourallah AW, Splieth CH, Schwahn C, Khurdaji M. Standardizing interarch tooth-size harmony in a Syrian population. Angle Orthod. 2005;75(6):996-9.

16. Al Sabbagh R. Syrian norms of menamara cephalometric analysis. Int Arab J Dent. 2014;392(3561):1-7.

17. Csiki I, Jianu R, Stratul S-I, Vegh A. Are the ricketts norms adequate for middle European adolescents? Timisoara Med J. 2008;58(1-2):74-7.

18. Gurdán Z, Marada G, Herényi G, Nagy Á. Examining tooth-size discrepancies in regard to treatment, treatment planning and completion. Open J Dent Oral Med. 2014;2(3):43-6.

19. Elsasser WA, Wylie WL. The craniofacial morphology of mandibular retrusion. Am J Phys Anthropol. 1948;6(4):461-74

20. Isik F, Nalbantgil D, Sayinsu K, Arun T. A comparative study of cephalometric and arch width characteristics of Class II division 1 and division 2 malocclusions. Eur J Orthod. 2006;28(2):179-83.

21. Al-Khateeb EA, Al-Khateeb SN. Anteroposterior and vertical components of Class II division 1 and division 2 malocclusion. Angle Orthod. 2009;79(5):859-66.

22. de Freitas MR, dos Santos MAC, de Freitas KMS, Janson G, de Freitas DS, Henriques JFC. Cephalometric characterization of skeletal Class II, division 1 malocclusion in white Brazilian subjects. J Appl Oral Sci. 2005;13(2):198-203.

23. Demir A, Uysal T, Basciftci FA. Determination of skeletal and dental characteristics of Class II malocclusion. Turk J Orthod. 2005;18(3):205-14.

24. Altemus LA. Horizontal and vertical dentofacial relationships in normal and Class II division I malocclusion in girls 11-15 years. Angle Orthod. 1955;25(3):120-37.

25. Rothstein T, Yoon-Tarlie C. Dental and facial skeletal characteristics and growth of males and females with Class II, division 1 malocclusion between the ages of 10 and 14 (revisited)_Part I: characteristics of size, form, and position. Am J Orthod Dentofacial Orthop. 2000;117(3):320-32.

26. Sayın MO, Türkkahraman $\mathrm{H}$. Cephalometric evaluation of nongrowing females with skeletal and dental Class II, division 1 malocclusion. Angle Orthod. 2005;75(4):656-60. 
27. Oh E, Ahn S-J, Sonnesen L. Ethnic differences in craniofacial and upper spine morphology in children with skeletal Class II malocclusion. Angle Orthod. 2018;88(3):283-91.

28. Hulley SB, Cummings SR, Browner WS, Grady DG, Newman TB. Designing clinical research. Wolters Kluwer Health; 2013.

29. Baccetti T, Franchi L, McNamara JA Jr. An improved version of the cervical vertebral maturation (CVM) method for the assessment of mandibular growth. Angle Orthod. 2002;72(4):316-23.

30. Jarabak JR, Fizzell JA. Technique and treatment with light-wire edgewise appliances, ed. 2, St. 1972.

31. Steiner CC. Cephalometrics for you and me. Am J Orthod. 1953;39(10):729-55.

32. Bhatia SN, Leighton BC. Manual of facial growth: a computer analysis of longitudinal cephalometric growth data. Oxford: Oxford University Press, Inc.; 1993.
33. Moorrees CFA, Reed RB. Correlations among crown diameters of human teeth. Arch Oral Biol. 1964;9(6):685-97.

34. Bolton WA. Disharmony in tooth size and its relation to the analysis and treatment of malocclusion. Angle Orthod. 1958;28(3):113-30.

35. Dahlberg G. Statistical methods for medical and biological students. London: George Alien and Unwin Ltd; 1940.

\section{Publisher's Note}

Springer Nature remains neutral with regard to jurisdictional claims in published maps and institutional affiliations.
Ready to submit your research? Choose BMC and benefit from:

- fast, convenient online submission

- thorough peer review by experienced researchers in your field

- rapid publication on acceptance

- support for research data, including large and complex data types

- gold Open Access which fosters wider collaboration and increased citations

- maximum visibility for your research: over 100M website views per year

At BMC, research is always in progress.

Learn more biomedcentral.com/submissions 